\title{
EVALUATION OF THE JAK2V617F MUTATIONAL BURDEN IN PATIENTS WITH PHILADELPHIA CHROMOSOME NEGATIVE MYELOPROLIFERATIVE NEOPLASMS: A SINGLE-CENTER EXPERIENCE
}

\begin{abstract}
Popova-Labachevska $\mathrm{M}^{1}$, Panovska-Stavridis I ${ }^{1, *}$, Eftimov A², Kapedanovska Nestorovska ${ }^{2}$,
\end{abstract} Cevreska L ${ }^{1}$, Ivanovski $\mathrm{M}^{1}$, Ridova $\mathrm{N}^{1}$, Trajkova $\mathrm{S}^{1}$, Dimovski AJ ${ }^{2, *}$

\begin{abstract}
*Corresponding Authors: Associate Professor Irina Panovska-Stavridis, M.D., Ph.D., University Clinic of Hematology, UKIM-Faculty of Medicine, University Cyril and Methodious," Majka Tereza 47, Skopje, RN Macedonia. Tel/Fax: +38923111749. E-mail: ukhematologija@t.mk and/or Professor Aleksandar J. Dimovski, M.D., Ph.D., Center for Biomolecular Pharmaceutical Analyses, UKIM-Faculty of Pharmacy, University "Ss Cyril and Methodius," Majka Tereza 47, Skopje, RN Macedonia. Tel/Fax: +38923119694. E-mail: adimovski@fff.ukim.edu.mk
\end{abstract}

\begin{abstract}
The identification of the JAK2V617F mutation in several distinct myeloproliferative neoplasms (MPNs) raised the question how one single mutation incites expression of at least three different clinical phenotypes, i.e., polycythemia vera (PV), essential thrombocythemia (ET) and primary myelofibrosis (PMF). In order to further evaluate already published data on the correlation between mutant JAK2V617F allele burden and specific hematological and clinical parameters, we tested the level of the JAK2 mutation in $134 \mathrm{JAK} 2+$ patients with different MPNs. The patients were diagnosed according to the 2008 WHO criteria and followed for a median of 48 months. The JAK2 V617F quantification was done with a real time polymerase chain reaction (real time-PCR) method. The median allele burden was lowest in ET (25.8\%), followed by $34.6 \%$ in PV and $51.8 \%$ in PMF patients $(p<0.01)$. There was statistically significant association between the mutational load of $10.0-50.0 \%$ and blood count parameters in the PV patients $(p<0.05)$. In PMF patients the mutational load was in correlation with older age and leukocyte count that were higher in patients with the mutational load of 10.0$50.0 \%$ and $>50.0 \%$ compared to those with a mutational load of $<10.0 \%$. There were no statistically significant associations between the allele burden and blood counts

\footnotetext{
${ }^{1}$ University Clinic of Hematology, UKIM-Faculty of Medicine, University "Ss Cyril and Methodius," Skopje, RN Macedonia

${ }^{2}$ Center for Biomolecular Pharmaceutical Analyses, UKIM-Faculty of Pharmacy, University "Ss Cyril and Methodius," Skopje, RN Macedonia
}

in the ET cohort. Our study confirmed an association between the JAK2V617F allele burden and the distinct MPN phenotypes, indicating unfavorable prognosis in patients with a higher JAK2 allele burden. Our results suggest that JAK2 quantification should be incorporated in the diagnostic work-up of MPN patients as a useful tool for optimal treatment decision.

Keywords: Allele burden; JAK2V617 mutation; Myeloproliferative neoplasms (MPNs).

\section{INTRODUCTION}

Polycythemia vera (PV), essential thrombocythemia (ET) and primary myelofibrosis (PMF) are classical Philadelphia-negative (Ph-negative) myeloproliferative neoplasms (MPNs) characterized by a clonal expansion of the abnormal hematopoietic stem/progenitor cell [1]. Their natural history is marked by thrombohemorrhagic episodes and a potential for transformation in myelofibrosis (PV and ET) or acute leukemia (PMF and PV). The major goal of therapy is prevention and/or treatment of these complications [2]. For many years, there were no specific histological, cytogenetic, or molecular markers for these MPNs.

The discovery of the unique gain-of-function somatic JAK2V617F mutation in patients with myeloproliferative disorders changed the diagnostic landscape of MPNs $[3,4]$. The mutation was found with a frequency of $>95.0 \%$ in PV patients and 55.0-60.0\% in ET and PMF patients, and it was soon adopted as a molecular criterion for these patients. It also helped delineate the molecular pathogenesis as well as the biological features of positive MPN patients [4]. Nevertheless, the "inquiry" how one single 
JAK2 V617F mutation incites expression of at least three different clinical phenotypes, i.e., PV, ET and PMF, is still open [5]. In the past few years, different hypotheses were proposed. One of them, named "the gene dosage hypothesis," postulates a counterpart between clinical manifestations and the proportion of JAK2 (V617F) mutant alleles introducing the concept of allele burden or "mutational load theory" (ratio between a mutant and wild type JAK2 in hematopoietic cells) [5-7].

The studies that followed supported this hypothesis and showed that the JAK2V617F mutational load was associated with specific hematological, clinical parameters and different risks for thromboembolic complications [6]. Those results indicate that allele burden testing could be incorporated in the initial diagnostic work-up as additional parameters for patient risk stratification [7]. In order to further clarify these observations, we evaluated the level of the JAK2 mutant allele and its clinical implications in 134 JAK2V617F+ patients with different MPNs from the RN Macedonia.

\section{MATERIALS AND METHODS}

A total of 134 patients with JAK2V617F+MPNs, namely, 17 patients with PV, 71 with ET and 46 with PMF, who were diagnosed and followed at the University Clinic of Hematology, Skopje, RN Macedonia, were included in the study. The diagnosis was made according to the 2008 WHO criteria and the median follow up period was 48 months (range 12-216). The median age of the patients at diagnosis was 53.5 years (range 19-88).

The presence of the JAK2V617 mutation was tested with a fluorescent allele-specific polymerase chain reaction (PCR) following procedures described in detail elsewhere
[8]. Representative results of quantification on the JAK2 V617F mutation level are shown in Figure 1. Each analysis included four control samples with 0.3, 3.0, 23.0 and $75.0 \%$ of the mutant allele (obtained within the Inter-Laboratory Quality Control Scheme organized by the MPN\& MPNr EuroNet in 2015) that were used for the creation of JAK2V617F standard curves. All samples, including the control samples, were analyzed in triplicate. The number of copies of the mutant [CN(V617F)] and the wild type $[\mathrm{CN}(\mathrm{WT})]$ alleles were calculated using the formulas $\mathrm{CN}(\mathrm{V} 617 \mathrm{~F})=-\operatorname{antilog}[\mathrm{Ct}(\mathrm{V} 617 \mathrm{~F})-39,662) / 3.6196]$ and $\mathrm{CN}(\mathrm{WT})=-\operatorname{antilog}[(\mathrm{Ct}(\mathrm{WT})-37.847) / 3.65]$, respectively, where the $\mathrm{Ct}$ (threshold cycle) value for each sample was the cycle in which the fluorescence of the sample crossed the predetermined threshold (usually set to 0.1 ). The final quantification of the amount of the mutant JAK2V617F in each specimen was calculated according to the following formula: \%JAK2V617F $=[\mathrm{CN} J A K 2 \mathrm{~V} 617 \mathrm{~F} /(\mathrm{CNJAK} 2$ $\mathrm{V} 617 \mathrm{~F}+\mathrm{CN}$ JAK2 WT) $] \times 100$.

The quantitative results of the JAK2 mutational status were correlated with the different MPN entities and the clinical and laboratory findings in each patient. The correlation of the allele burden with various clinical parameters was done by Mann-Whitney and Kruskal Wallis student's tests using the Statgraphics 4.3 software (www. statpoint. com).

\section{RESULTS}

In our study, allele burden quantification was performed during the initial diagnostic work-up. Based on the amount of mutational load, the patients were divided into three groups: those with $<10.0 \%$ mutational load, those with a mutational status of $10.0-50.0 \%$ and those with

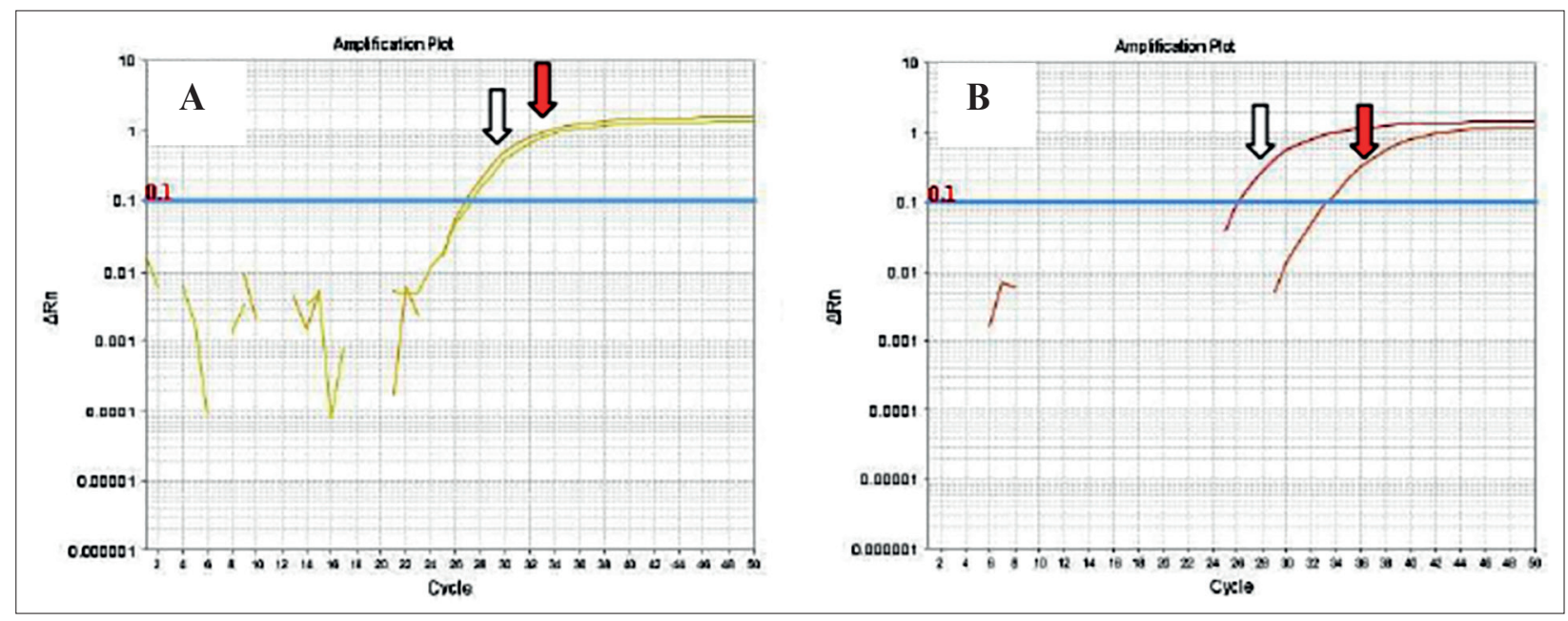

Figure 1. Results from the quantitative allele specific real-time PCR experiment in patients with $56.2 \%(\mathrm{~A})$ and $5.5 \%$ (B) JAK2V617F mutation levels. The white arrow marks the normal allele and the red arrow the mutant allele. 
$>50.0 \%$ mutational load. Clinical and laboratory data at diagnosis were obtained from the patients' charts according to the protocol approved by the Institutional Review Board of the University Clinic of Hematology, Skopje, RN Macedonia. Our study showed that the median allele burden was the lowest in patients with ET (25.8\%), followed by PV patients (34.6\%) and PMF patients (51.8\%) $(p<0.01)$ with a statistically significant difference of the percentage of mutant alleles between ET and PMF patients $(p<0.00001)$, between PMF and PV patients $(p<0.05)$, but not between ET and PV patients $(p=0.38)$ (Figure 2 and Table 1).

The comparison between the clinical and hematological findings in JAK2V617F+ET and the allele burden of the JAK2V617F is presented in Table 2. In the group of 71 ET patients, 14 (19.7\%), 50 patients $(70.4 \%)$ and seven patients $(9.9 \%)$ had a mutational load of $<10.0,10.0-50.0$ and $>50.0 \%$, respectively. No association was observed between the allele burden and the clinical and laboratory features in the ET group.

The clinical and hematological findings in JAK2 $\mathrm{V} 617 \mathrm{~F}+\mathrm{PV}$ in association with the allele burden of the

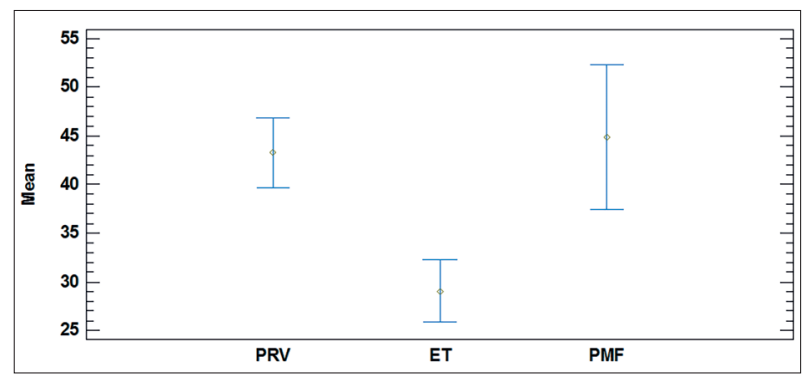

Figure 2. The mean \pm SD $(95 \% \mathrm{CI})$ of JAK2V617F allele burden in 134 patients with different types of Ph-negative MPNs.

JAK2 V617F are presented in Table 3. In 17 patients with $\mathrm{PV}$, four (23.5\%), eight (47.1\%) and five (29.4\%) patients had mutational loads of $<10.0,10.0-50.0$ and $>50.0 \%$, respectively $(p<0.7)$. The comparison of the allele burden with hematological parameters in the PV group, revealed the highest platelet count in PV patients with a mutational load of 10.0-50.0\% (578.8, range 371.9-785.8) (for overall comparison $p<0.05$ ), but no significant correlation was found in the hemoglobin $(\mathrm{Hb})$ level, packed cell volume (PCV) and white blood cell (WBC) counts.

Table 1. The JAK2V617F allele burden in 134 patients with different types of Ph-negative MPNs.

\begin{tabular}{|l|c|c|c|c|c|c|c|}
\hline Diagnosis & ET $(\boldsymbol{n}=\mathbf{7 1})$ & $\mathbf{P V ~}(\boldsymbol{n}=\mathbf{1 7})$ & $\mathbf{P M F}(\boldsymbol{n}=\mathbf{4 6})$ & $\begin{array}{c}\boldsymbol{p} \text { Value } \\
(\text { Kruskal-Wallis test) }\end{array}$ & $\begin{array}{c}\boldsymbol{p} \text { Value }^{\mathrm{a}} \\
\text { ET/PMF }\end{array}$ & $\begin{array}{c}\boldsymbol{p} \text { Value }^{\mathrm{a}} \\
\text { ET/PV }\end{array}$ & $\begin{array}{c}\boldsymbol{p} \text { Value }^{\mathrm{a}} \\
\text { ET/PMF }\end{array}$ \\
\hline $\begin{array}{l}\text { JAK2V617F allele burden } \\
\text { Mean+SD (95\% (CI) }\end{array}$ & $\begin{array}{c}25.54 \pm 20.82 \\
(20.61-30.46)\end{array}$ & $\begin{array}{c}34.65 \pm 27.39 \\
(20.57-48.74)\end{array}$ & $\begin{array}{c}51.83 \pm 25.49 \\
(44.26-59.40)\end{array}$ & 0.000001 & $<0.0001$ & 0.3551 & 0.0258 \\
\hline
\end{tabular}

ET: essential thrombocythemia; PV: polycythemia vera; PMF: primary myelofibrosis; mean \pm SD: mean \pm standard deviation; $95 \%$ CI: $95 \%$ confidence interval.

${ }^{a} p$ Values were calculated using the Mann-Whitney test (independent samples) if the $p$ value (Kruskal-Wallis test) was $<0.05$.

Table 2. Clinical and hematological findings in 71 JAK2V617F+ET patients in comparison with JAK2V617F allele burden. ${ }^{a}$

\begin{tabular}{|c|c|c|c|c|c|c|c|}
\hline Allele Burden (\%) & $<10.0 \%$ & $10.0-50.0 \%$ & $>50.0 \%$ & $\begin{array}{c}p \text { Value }^{\mathrm{a}} \\
\text { (Kruskal-Wallis test) }\end{array}$ & $\begin{array}{l}p \text { Value }{ }^{\mathrm{b}} \\
\text { ET/PMF }\end{array}$ & $\begin{array}{c}p \text { Value }^{\mathrm{b}} \\
\text { ET/PV }\end{array}$ & $\begin{array}{l}p \text { Value }^{\text {b }} \\
\text { ET/PMF }\end{array}$ \\
\hline$n(\%)$ patients & 14 (19.718) & $50(70.423)$ & $7(9.859)$ & & & & \\
\hline Age & $\begin{array}{c}59.75 \pm 14.76 \\
(50.38-69.13)\end{array}$ & $\begin{array}{c}59.64 \pm 14.56 \\
(55.50-63.78)\end{array}$ & $\begin{array}{c}61.14 \pm 18.13 \\
(44.37-77.91)\end{array}$ & 0.998 & $>0.05$ & $>0.05$ & $>0.05$ \\
\hline WBC $\left(10^{9} / \mathrm{L}\right)$ & $\begin{array}{l}8.08 \pm 1.73 \\
(6.98-9.18)\end{array}$ & $\begin{array}{c}9.21 \pm 3.35 \\
(8.26-10.16)\end{array}$ & $\begin{array}{c}8.96 \pm 2.93 \\
(6.258-11.67) \\
\end{array}$ & 0.631 & $>0.05$ & $>0.05$ & $>0.05$ \\
\hline $\mathrm{RBC}\left(10^{12} / \mathrm{L}\right)$ & $\begin{array}{c}4.43 \pm 0.64 \\
(4.02-4.84)\end{array}$ & $\begin{array}{l}4.56 \pm 0.63 \\
(4.38-4.74)\end{array}$ & $\begin{array}{l}4.84 \pm 1.07 \\
(3.85-5.84)\end{array}$ & 0.820 & $>0.05$ & $>0.05$ & $>0.05$ \\
\hline $\mathrm{Hb}(\mathrm{g} / \mathrm{dL})$ & $\begin{array}{c}14.17 \pm 14.91 \\
(13.23-15.12)\end{array}$ & $\begin{array}{c}14.26 \pm 12.92 \\
(13.89-14.63)\end{array}$ & $\begin{array}{c}13.96 \pm 10.88 \\
(12.98-14.99)\end{array}$ & 0.925 & $>0.05$ & $>0.05$ & $>0.05$ \\
\hline $\mathrm{PCV}(\mathrm{L} / \mathrm{L})$ & $\begin{array}{c}0.42 \pm 0.04 \\
(0.40-0.05)\end{array}$ & $\begin{array}{c}0.43 \pm 0.04 \\
(0.42-0.04)\end{array}$ & $\begin{array}{c}0.46 \pm 0.04 \\
(0.39-0.05)\end{array}$ & 0.584 & $>0.05$ & $>0.05$ & $>0.05$ \\
\hline Platelets $\left(10^{9} / \mathrm{L}\right)$ & $\begin{array}{c}947.33 \pm 282.28 \\
(767.98-1126.68)\end{array}$ & $\begin{array}{c}958.48 \pm 301.26 \\
(872.86-1044.09)\end{array}$ & $\begin{array}{c}861.14 \pm 225.29 \\
(652.78-1069.50)\end{array}$ & 0.255 & $>0.05$ & $>0.05$ & $>0.05$ \\
\hline
\end{tabular}

${ }^{\text {a }}$ All values are given as mean $\pm \mathrm{SD}(95 \% \mathrm{CI})$.

${ }^{\mathrm{b}} p$ Values was provided using the Mann-Whitney test (independent samples) if the $p$ value (Kruskal-Wallis test) was $<0.05$. 
Table 3. Clinical and hematological findings in $17 \mathrm{JAK} 2 \mathrm{~V} 617 \mathrm{~F}+\mathrm{PV}$ patients in comparison withJAK2V617F allele burden. ${ }^{\mathrm{a}}$

\begin{tabular}{|c|c|c|c|c|c|c|c|}
\hline Allele Burden (\%) & $<10.0 \%$ & $10.0-50.0 \%$ & $>50.0 \%$ & $\begin{array}{c}p \text { Value }^{\mathrm{a}} \\
\text { (Kruskal-Wallis test) }\end{array}$ & $\begin{array}{l}p \text { Value }^{\mathrm{b}} \\
\text { ET/PMF }\end{array}$ & $\begin{array}{l}p \text { Value }^{\mathrm{b}} \\
\text { ET/PV }\end{array}$ & $\begin{array}{l}p \text { Value }^{\mathrm{b}} \\
\text { ET/PMF }\end{array}$ \\
\hline$n(\%)$ patients & $4(23.53)$ & $8(47.06)$ & $5(29.41)$ & & & & \\
\hline Age & $\begin{array}{c}57.00 \pm 16.22 \\
(47.10-66.89)\end{array}$ & $\begin{array}{c}58.00 \pm 18.41 \\
(42.61-73.39)\end{array}$ & $\begin{array}{c}63.80 \pm 11.39 \\
(49.66-77.94)\end{array}$ & 0.496 & $>0.05$ & $>0.05$ & $>0.05$ \\
\hline $\mathrm{WBC}\left(10^{9} / \mathrm{L}\right)$ & $\begin{array}{l}111.50 \pm 5.80 \\
(2.27-20.73)\end{array}$ & $\begin{array}{c}9.14 \pm 1.72 \\
(7.70-10.57)\end{array}$ & $\begin{array}{c}8.74 \pm 3.29 \\
(4.65-12.83)\end{array}$ & 0.867 & $>0.05$ & $>0.05$ & $>0.05$ \\
\hline $\mathrm{RBC}\left(10^{12} / \mathrm{L}\right)$ & $\begin{array}{c}6.35 \pm 0.94 \\
(4.85-7.85)\end{array}$ & $\begin{array}{c}6.41 \pm 0.92 \\
(5.64-7.17)\end{array}$ & $\begin{array}{c}5.82 \pm 2.30 \\
(2.96-8.68)\end{array}$ & 0.956 & $>0.05$ & $>0.05$ & $>0.05$ \\
\hline $\mathrm{Hb}(\mathrm{g} / \mathrm{dL})$ & $\begin{array}{c}20.25 \pm 15.26 \\
(17.82-22.68)\end{array}$ & $\begin{array}{c}18.52 \pm 21.12 \\
(16.80-20.23)\end{array}$ & $\begin{array}{c}18.26 \pm 49.34 \\
(12.13-24.39)\end{array}$ & 0.523 & $>0.05$ & $>0.05$ & $>0.05$ \\
\hline $\mathrm{PCV}(\mathrm{L} / \mathrm{L})$ & $\begin{array}{c}0.58 \pm 0.05 \\
(0.49-0.07)\end{array}$ & $\begin{array}{c}0.56 \pm 0.38 \\
(0.53-0.06)\end{array}$ & $\begin{array}{c}0.55 \pm 0.01 \\
(0.40-0.07)\end{array}$ & 0.921 & $>0.05$ & $>0.05$ & $>0.05$ \\
\hline Platelets $\left(10^{9} / \mathrm{L}\right)$ & $\begin{array}{c}295.00 \pm 87.74 \\
(155.38-434.62)\end{array}$ & $\begin{array}{c}578.87 \pm 247.55 \\
(371.92-785.84)\end{array}$ & $\begin{array}{c}292.00 \pm 105.52 \\
(160.98-423.02)\end{array}$ & 0.034 & 0.041 & 1.00 & 0.028 \\
\hline
\end{tabular}

${ }^{a}$ All values are given as mean $\pm \mathrm{SD}(95 \% \mathrm{CI})$.

${ }^{\mathrm{b}} p$ Values was provided using the Mann-Whitney test (independent samples) if the $p$ value (Kruskal-Wallis test) was $<0.05$.

Table 4. Clinical and hematological findings in 46 JAK2V617F+PMF patients in comparison with JAK2V617F allele burden.a

\begin{tabular}{|c|c|c|c|c|c|c|c|}
\hline Allele Burden (\%) & $<10.0 \%$ & $10.0-50.0 \%$ & $>50.0 \%$ & $\begin{array}{c}p \text { Value }^{\mathrm{a}} \\
\text { (Kruskal-Wallis test) }^{-}\end{array}$ & $\begin{array}{l}p \text { Value }^{\mathrm{b}} \\
\text { ET/PMF }\end{array}$ & $\begin{array}{c}p \text { Value }^{\mathrm{b}} \\
\text { ET/PV }\end{array}$ & $\begin{array}{l}p \text { Value }^{\mathrm{b}} \\
\text { ET/PMF }\end{array}$ \\
\hline$n(\%)$ patients & $3(6.52)$ & $17(36.96)$ & $26(65.52)$ & & & & \\
\hline Age & $\begin{array}{c}53.33 \pm 16.50 \\
(12.34-94.33)\end{array}$ & $\begin{array}{c}60.59 \pm 14.31 \\
(53.23-67.95)\end{array}$ & $\begin{array}{c}69.23 \pm 9.05 \\
(65.574-72.887)\end{array}$ & 0.052 & 0.427 & 0.078 & 0.048 \\
\hline WBC $\left(10^{9} / \mathrm{L}\right)$ & $\begin{array}{c}8.67 \pm 2.08 \\
(3.49-13.84)\end{array}$ & $\begin{array}{c}12.76 \pm 8.61 \\
(8.34-17.19)\end{array}$ & $\begin{array}{c}17.89 \pm 9.47 \\
(14.07-21.72)\end{array}$ & 0.021 & 0.289 & 0.035 & 0.031 \\
\hline $\operatorname{RBC}\left(10^{12} / \mathrm{L}\right)$ & $\begin{array}{c}5.33 \pm 1.15 \\
(2.46-8.20)\end{array}$ & $\begin{array}{c}5.64 \pm 1.49 \\
(4.88-6.41)\end{array}$ & $\begin{array}{c}5.04 \pm 1.28 \\
(4.52-5.55)\end{array}$ & 0.399 & $>0.05$ & $>0.05$ & $>0.05$ \\
\hline $\mathrm{Hb}(\mathrm{g} / \mathrm{dL})$ & $\begin{array}{c}15.03 \pm 26.27 \\
(85.07-21.56)\end{array}$ & $\begin{array}{c}16.95 \pm 32.99 \\
(11.53-18.65)\end{array}$ & $\begin{array}{c}16.18 \pm 37.00 \\
(14.66-17.71)\end{array}$ & 0.369 & $>0.05$ & $>0.05$ & $>0.05$ \\
\hline $\mathrm{PCV}(\mathrm{L} / \mathrm{L})$ & $\begin{array}{c}0.46 \pm 0.09 \\
(0.22-0.07)\end{array}$ & $\begin{array}{c}0.52 \pm 0.10 \\
(0.47-0.06)\end{array}$ & $\begin{array}{c}0.50 \pm 0.10 \\
(0.46-0.05)\end{array}$ & 0.373 & $>0.05$ & $>0.05$ & $>0.05$ \\
\hline Platelets $\left(10^{9} / \mathrm{L}\right)$ & $\begin{array}{c}707.67 \pm 140.65 \\
(358.28-1057.05)\end{array}$ & $\begin{array}{c}777.71 \pm 391.21 \\
(576.56-978.85)\end{array}$ & $\begin{array}{c}781.42 \pm 251.76 \\
(676.73-883.11)\end{array}$ & 0.950 & $>0.05$ & $>0.05$ & $>0.05$ \\
\hline
\end{tabular}

${ }^{\text {a }}$ All values are given as mean $\pm \mathrm{SD}(95 \% \mathrm{CI})$.

${ }^{\mathrm{b}} p$ Values was provided using the Mann-Whitney test (independent samples) if the $p$ value (Kruskal-Wallis test) was $<0.05$.

In the group of PMF patients, a higher mutational load was associated with older age (53.3, range 12.3-94.3, 60.6 , range 53.2-67.9, and 69.2, range 65.6-72.9, for mutational load $<10.0,10.0-50.0$ and $>50.0 \%$, respectively). The results showed that PMF patients with a mutational load of 10.0-50.0 and $>50.0 \%$, had a higher WBC count than those with a mutational load of $<10.0 \%$ (12.8, range 3.5-13.8, 17.8, range 8.3-17.2, and 8.6, range 14.1-21.7, respec-tively). No statistically significant difference was observed in the comparison of the platelet (plt) count, PCV and $\mathrm{Hb}$ levels between patients with a mutational load of $<10.0,10.0-50.0$ and $>50.0 \%$ (Table 4 ).

\section{DISCUSSION}

In an attempt to explain the association of the single mutation with three different clinical phenotypes, the genedosage hypothesis postulates that the ratio between the mutant type and wild JAK2 type in hematopoietic cells influences the expression of the clinical phenotype [5-7]. As 
patients with MPNs often present with overlapping clinical signs, symptoms and morphological findings, several studies have been conducted to test this hypothesis [5-7]. They have shown that the JAK2 mutational load is associated with specific hematological and clinical parameters in different MPN entities [9]. It has been suggested that a mutant allele burden of $>50.0 \%$ is associated with older age, clinical signs and symptoms of PV, a more severe clinical course with a higher rate of thrombosis and a faster progression to myelofibrosis compared to a mutant allele burden $<50.0 \%$ $[9,10]$. Other studies showed that the JAK2 allele burden could be used for stratification of patients into subgroups associated with different frequency of complications [9].

Although, the WHO criteria does not specify a cutoff value for the diagnosis of a specific MPN, the determination of the mutational load is becoming a potential diagnostic procedure in most molecular laboratories worldwide and, in addition, it may be useful in evaluating the response to therapy [1]. Another perspective of the evaluation of the allele burden is its utility as a follow-up tool during the treatment of JAK2V617F positive patients [9]. However, the specific utility of the JAK2V617F allele burden for measuring the MPN patients' response to treatment is yet to be established [11].

In our group of patients, there was a statistically significant difference in the percentage of the mutant allele between ET and PMF patients $(p<0.00001)$ and between PV and PMF patients $(p<0.05)$, but not between PV and ET patients $(p=0.38)$. These findings are consistent with several previous studies that showed a significantly higher JAK2 allele burden in PV and PMF patients in contrast to ET patients [9].

Several studies have discussed the JAK2 allele burden impact on disease transformation and its utility in predicting disease transformation $[9,10]$. Our results showed that in the presence of a higher $\mathrm{V} 617 \mathrm{~F}$ allele burden, a diagnosis of PV and PMF should be strongly considered, because the burden of the mutated allele correlates with the MPN phenotype and a major clinical endpoint [9-11].

\section{CONCLUSIONS}

Our findings support the concept that the phenotypic presentation of the specific MPN is influenced by the JAK2V617F mutational load. Moreover, they are consistent with the already published data that $>50.0 \%$ mutational load of the JAK2V617F mutation could have a predictive value regarding the clinical course and evolution of the specific MPN entity. They also suggest that the implementation of the JAK2 allele burden in a routine diagnostic work-up of MPN patients could be a useful tool for the refinement of the optimal treatment option [11].
Declaration of Interest. The authors report no conflicts of interest. The authors alone are responsible for the content and writing of this article.

Funding. This study was funded (in part) by research funds of the Center for Biomolecular Pharmaceutical Analyses, UMIM-Faculty of Pharmachy, Skopje, RN Macedonia (to AJD).

\section{REFERENCES}

1. Barbui T, Thiele J, Gisslinger H, Kvasnicka HM, Vannucchi AM, Guglielmelli P, et al. The 2016 WHO classification and diagnostic criteria for myeloproliferative neoplasms: document summary and in-depth discussion. Blood Cancer J. 2018; 8(2): 15-25.

2. Vannucchi AM, Harrison CN. Emerging treatment for classical myeloproliferative neoplasms. Blood. 2017; 129(6): 693-703.

3. Kralovics R, Passamonti F, Buser AS, Teo SS, Tiedt $\mathrm{R}$, Passweg JR, et al. A gain-of-function mutation of JAK2 in myeloproliferative disorders. N Engl J Med. 2005; 352(17): 1779-1790.

4. Singdong R, Siriboonpiputtana T, Chareonsiri-suthigul T, Kongruang A, Limsuwanachot N, Sirirat T, et al. Characterisation and prognosis significance of JAK2 (V617F), MPL and CALR mutations in Philadelphia negative myeloproliferative neoplasms. Asian Pac J Cancer Prev. 2016; 17(10): 4647-4653.

5. Alshemmari SH, Rajaan R, Ameen R, Al-Drees MA, Almosailleakh MR. JAK2V617F allele burden in patients with myeloproliferative neoplasms. Ann Hematol. 2014; 93(5): 791-796.

6. Perricone M, Polverelli N, Martinelli G, Catani L, Ottaviani E, Zuffa E, et al. The relevance of a low JAK2 V617F allele burden in clinical practice: A monocentric study. Oncotarget. 2017; 8(23): 3723937249.

7. Ha, JS, Kim YK, Jung SI, Jung HR, Chung, IS. Correlations between Janus Kinase 2V617F allele burdens and clinicohematologic parameters in myeloproliferative neoplasms. Ann Lab Med. 2012; 32(6): 385-391.

8. Jovanovic JV, Ivey A, Vannucchi AM, Lippert E, Oppliger Leibundgut E, et al. Establishing optimal quantitative-polymerase chain reaction assays for routine diagnosis and tracking of minimal residual disease in JAK2-V617F-associated myeloproliferative neoplasms: A joint European LeukemiaNet MPN\&MPNr-EuroNet (COST action BM0902) study. Leukemia. 2013; 27(10): 2032-2039. 
9. Malysz J, Crisan D. Correlation of JAK2 V617F mutant allele quantification with clinical presentation and type of chronic myeloproliferative neoplasm. Ann Clin Lab Sci. 2009; 39(4): 345-350.

10. Antonioli E, Guglielmelli P, Poli G, Bogani C, Pancrazzi A, Longo G, et al. Influence of JAK2V617F allele burden on phenotype in essential thrombocythemia. Haematologica. 2008; 93(1): 41-48.
11. Silver RT, Vandris K, Wang YL, Adriano F, Jones AV, Christos PJ, et al. JAK2V617F allele burden in polycythemia vera correlates with grade of myelofibrosis, but is not substantially affected by therapy. Leukemia Res. 2011; 35(2): 177-182. 